\title{
Educação popular e sua renovação crítica: um diá- logo com as Epistemologias do Sul
}

\author{
Sérgio Roberto Moraes Corrêa \\ Universidade do Estado do Pará \\ Severino Bezerra da Silva \\ Universidade Federal da Paraíba
}

\section{Resumo}

$\bigcirc$ presente artigo se propõe a fazer uma reflexão teórica e epistemológica sobre a Educação Popular (EP) no contexto da sociedade contemporânea de crises e mudanças paradigmáticas, especialmente no Brasil, procurando, a partir da periferia e dos (as) oprimidos (as), estabelecer um diálogo com as Epistemologias do Sul, em particular com Boaventura Santos, a fim de colocar novas questões e sujeitos em cena e debate, para pensar os desafios da renovação crítica da educação popular e identificar os desafios da reinvenção dos processos de emancipação social. Este artigo é resultado de uma dissertação de mestrado realizada no Programa de Pós-Graduação em Educação (PPGE) da Universidade Federal da Paraíba (UFPB).

Palavras-chave: Educação popular. Epistemologias do Sul. Emancipação social.

\section{Popular education and his/her critical renewal: a dialogue with episte- mologias of the South}

\section{Abstract}

The present article proposes a theoretical and epistemological reflection on the Popular Education (PE) in the context of a contemporary society of crisis and paradigmatic changes, especially in Brazil, searching, from the periphery and the oppressed, to establish a dialogue with the Southern Epistemologies, particularly Boaventura Santos, in order to put new questions and individuals in scene and debate, to think about the challenges of the critical renovation of popular education and identify the challenges of the reinvention of the processes of social emancipation. This article is the result of a master's thesis held in the Graduate Program in Education (PPGE) of UFPB.

Keywords: Popular education. Southern Epistemologies. Social emancipation. 


\section{Educación popular y su renovación crítica: un diálogo con las Epistemologías del Sur}

\section{Resumen}

El presente artículo se propone hacer una reflexión teórica y epistemológica sobre la Educación Popular (EP) en el contexto de la sociedad contemporánea de crisis y cambios paradigmáticos, especialmente en Brasil, buscando, desde la periferia y los oprimidos, establecer un diálogo con las Epistemologías del Sur, en particular con Boaventura Santos, para plantear nuevas cuestiones y sujetos en escena y debate, para pensar los desafíos de la renovación crítica de la educación popular e identificar los desafíos de la reinvención de los procesos de emancipación social. Este artículo es el resultado de una disertación de maestría realizada en el Programa de Postgrado en Educación (PPGE) de la UFPB.

Palabras clave: Educación popular. Epistemologías del Sur. Emancipación social.

\section{Introdução}

Em face das mudanças estruturais e conjunturais sem precedentes no mundo capitalista globalizado, os paradigmas epistemológicos da modernidade de apreensão da realidade social e seus objetos de estudos passam a ser tenazmente contestados. O ideário da razão iluminista, que colocava na razão humana o lume para felicidade e prosperidade do "homem fausto" é frustrado e desafiado a se confrontar consigo mesmo, com outras vozes plurais e outros paradigmas emergentes no terreno dessas mudanças e no território da geopolítica Norte-Sul, marcada pela relação desigual e conflitual no campo do conhecimento, do social, do econômico, do políitico, do cultural, do científico-tecnológico (SANTOS, 2006; SANTOS; MENEZES, 2010).

Nessa conjuntura, os conceitos de educação popular e de movimento social, também, são colocados em debate, apresentando limites, possibilidades e desafios (CALADO, 1998; FREIRE, 1992, 1996; FLEURI, 1998; GADOTTI, 2000; MEIÍA, 1996; SANTOS, 2006), conformando, por conseguinte, novos desafios e novas dimensões, para construção dessas alternativas e da utopia da transformação social. Isso reacende o terreno das relações de poder no campo da produção de conhecimento e da práxis político-social da educação popular e dos movimentos sociais populares nas territorialidades do campo e da cidade na sociedade brasileira. 
Assim, a educação popular, na atualidade, é posta sob clivagem: o que a educação popular tem a revelar quando vista sob as novas clivagens das Epistemologias do Sul sobre a modernidade eurocêntrica que pesa sobre a interpretação do Brasil e da sua educação? $\bigcirc$ que a educação popular tem a revelar quando vista sob as novas clivagens de novos atores e atrizes sociais que entram na arena, denunciando outras formas de dominação e opressão e reivindicando novas conquistas de direitos na sociedade brasileira?

Este texto compreende que o desafio da reinvenção crítica da educação popular não pode prescindir da relação dialética entre ontologia e epistemologia e de partir da "periferia" e das "vítimas" ou "oprimidos" do sistema capitalista e colonialista, que tomam a cena reivindicando o seu reconhecimento e direitos, pondo temas e problemas, além de uma relação estrutural de classes, considerando outras dimensões da sociedade contemporânea, em particular periférica do capitalismo (FREIRE, 1992; SANTOS, 2006; DUSSEL, 1993).

\section{A crise da ciência moderna: uma crítica a partir das Epistemologias do}

202 Sul

Para Santos (2002, 2004), esse é um tempo histórico de transição paradigmática tanto epistemológica, como social e política, em que todas as certezas são contestadas e entram em conflitos estruturais. Isso significa assinalar mudanças e novos problemas que as teorias modernas eurocêntricas parecem carecer de respostas. Há uma crítica epistemológica ao paradigma hegemônico da ciência moderna, cuja melhor elaboração fora o positivismo. Esse paradigma expressa uma forte crise e recai sobre ele uma grande desconfiança de não contemplar os desafios propostos pela própria modernidade: igualdade, fraternidade, liberdade, justiça, solidariedade e democracia. Para Santos, os pressupostos desse paradigma evidenciam sua crise nas seguintes ideias:

[...] distinção entre sujeito e objeto e entre natureza e sociedade ou cultura; redução da complexidade do mundo a leis simples susceptíveis de formulação matemática; uma concepção da realidade dominada pelo mecanicismo determinista e de verdade como representação transparente da realidade; uma separação absoluta 
entre conhecimento científico - considerado o único e válido - e outras formas de conhecimento como o senso comum ou estudos humanísticos; privilegiamento da causalidade funcional, hostil à investigação das "causas últimas", consideradas metafísicas, e centradas na manipulação e transformação da realidade estudada pela ciência (SANTOS, 2004, p. 1-2).

No curso de seu desenvolvimento, esse paradigma se consolida hegemonicamente, apresentando-se como modelo universal de racionalidade para apreender e explicar o mundo, fundado nessa matriz de ciência eurocêntrica, que deslegitima os demais modos de se autorrepresentar, de existir e produzir saberes, culturas e formas de sociabilidades. A sociedade capitalista, ideologicamente, conforme os pressupostos epistemológicos e regras metodológicas desse paradigma positivista, é apresentada, metaforicamente, como "mundo-máquina", ou seja, uma ordem social natural mecânica e imutável (SANTOS, 2005). Esse paradigma é produto e produtor de um discurso ideológico e imaginário eurocêntricos, que construíram e sustentaram sua suposta legitimidade sobre os povos colonizados à luz da validade "universal" e "natural" da ciência moderna (LANDER, 2005).

Esse paradigma foi fundamental para justificar o projeto capitalista moderno-colonialista de dominação do mundo, que teve início no final do século XV e início do XVI, o que seria o nascedouro do fenômeno da globalização colonialista. Como parte desse ambicioso projeto, a Terra Brasilis e - Vale Amazônico, ou a Amazônia, foram fundados, assim como as demais "periferias" desse projeto, sobre esse ideário eurocêntrico, um olhar de fora, que impôs um modo de ser, pensar, sentir e agir como modelo universal, uma classificação social (QUIJANO, 2005) sendo, no entanto, essencialmente particular, isto é: "[...] institui-se uma universalidade radicalmente excludente [...]" (LANDER, 2005, p. 27) de outros modos de vida, de saberes e culturas e de imaginários. Para Dussel (1993), a "modernidade" ocidental surge com o "encobrimento" de outros povos, culturas, saberes, modos de existir (ethos), demarcando esse processo de colonização e pseudo "descobrimento" pela via da instauração da violência institucional da modernidade, o que expressa, de fato, um movimento de contradição e de conflitos candentes, posto as ações de resistências sociais pelos povos oprimidos a tal empreendimento colonial.

É importante, contudo, considerar, como advertem Santos, Meneses e Nunes (2005, p. 98), que o "[...] privilégio epistemológico da ciência moderna 
Educação popular e sua renovação crítica: um diálogo com as Epistemologias do Sul

é um fenômeno complexo que não é explicável apenas por razões epistemológicas". Para eles (SANTOS, MENESES, NUNES, 2005, p. 98), esse privilégio epistemológico envolve, indissociavelmente, questões de ordem social, política e econômica que, ajudam a conformar uma ordem social hegemônica. Com isso, defendem a necessidade de que as pesquisas e os debates acerca da desigualdade epistemológica no mundo possam se articular e se relacionar dialeticamente às lutas contra as desigualdades socioeconômicas e políticas. É nesse sentido que, a descolonização da ciência assenta no reconhecimento de que "[...] não há justiça social global sem justiça cognitiva global. A justiça cognitiva global só é possível mediante a substituição da monocultura do saber científico pela ecologia dos saberes" (SANTOS, MENESES, NUNES, 2005, p. 100).

Ao formular uma interpretação do mundo, pensado a partir de um conhecimento eurocêntrico, esse paradigma se proclama e se julga o conhecimento do mundo, contudo, Santos (2006) sustenta e adverte que não é o conhecimento do mundo, mas um conhecimento particular sobre o mundo, que exclui e nega os demais conhecimentos, epistemes de outros sujeitos e lugares, da representação de seus modos de existir, de interpretar, explicar e intervir 204 no mundo. Esse conhecimento cientifico monocultural, portanto, é fundamentalmente autoritário e excludente, porque exclui o conflito e a diversidade, o que implica uma injustiça cognitiva, que está articulada às injustiças sociais, econômicas, políticas, culturais e ambientais do capitalismo. Apesar de Santos (2006) reconhecer a diferença entre eles (capitalismo e colonialismo), argumenta que ambos andam historicamente de mãos dadas nesse processo de dominação e opressão. Por isso, a construção de caminhos de resistência e de alternativas contra-hegemônicas passa tanto pela renovação da teoria crítica como pela reinvenção da emancipação social. Isso implica a crítica ao colonialismo e ao capitalismo conjuntamente, bem como ao patriarcado, e a identificação do Sul como terreno contraditório e conflitivo, que carrega a marca da violência capitalista, colonialista e patriarcal e da subalternidade dos povos e grupos sociais oprimidos, mas, também, de potência de sujeitos emergentes e de novas experiências sociais plurais e complexas.

Nessa conjuntura de globalização hegemônica, Santos, Meneses e Nunes (2005, p. 100) defendem a tese de que o "[...] colonialismo terminou enquanto relação política, mas não enquanto relação social, permanecendo sob a forma da colonialidade do poder", que é uma consequência da 
"colonialidade do saber científico" que vigora, historicamente, na relação entre o centro e as periferias do sistema mundial capitalista, redefinido e reafirmado nessa nova geografia global entre o Norte (centro, rico) e o Sul (periferia, pobre).

Nesse sentido, a globalização hegemônica é uma visão particular dos grupos hegemônicos, que impõe uma racionalidade de interpretar, explicar e mostrar o mundo atual seguindo o paradigma hegemônico da Razão Indolente (SANTOS, 2001). Santos (2004a, p. 779 a 788), num avanço de suas pesquisas e formulações, explica que essa Razão Indolente ocorre em quatro formas distintas: a "razão impotente"; a "razão arrogante"; a "razão metonímica" e a "razão proléptica". Ele centraliza seu estudo crítico nas duas últimas, em especial nesse seu texto, na "razão metonímica", que toma a parte pelo todo, expressando-se como totalidade e tempo linear, que produz não existências sociais, estreitando o presente e alargando o futuro. $\bigcirc$ autor adverte que não existe uma "maneira única ou unívoca de não existir, porque são várias as lógicas e os processos pelos quais a razão metonímica produz a não existência" e, por conseguinte, a classificação, hierarquização e exclusão social. Ele destaca cinco lógicas ou modos de produção da não existência: I) a monocultura do saber e do rigor do saber; II) a monocultura do tempo linear; III) a lógica da classificação social; IV) a lógica da escala dominante; e v) a lógica produtivista.

$\mathrm{Na}$ "Monocultura do saber moderno", um único saber válido é o da ciência moderna eurocêntrica, desconhecendo a validade e a racionalidade dos demais saberes. Na "Monocultura Classificatória", produz-se, socialmente, uma hierarquização entre saberes e entre as relações sociais. $\mathrm{Na}$ "Monocultura do Tempo Linear", a existência de um único sentido: a lógica do desenvolvimento e progresso. Santos faz uma distinção entre simultaneidade e contemporaneidade. Um exemplo posto pode ser a relação entre um grande grupo econômico mundial e um dado povo indígena, explicando que a relação pode até ser simultânea, mas o primeiro se apresenta como contemporâneo ao passo que o segundo é a representação do atraso, do tradicional, da inferioridade; o que implica uma lógica ou modo de produção de classificação e exclusão social. Na "Monocultura Produtiva", uma lógica única de produção, fundada e guiada pela ciência para o acúmulo do capital e exploração dos recursos naturais e da força de trabalho, tendo na racionalidade liberal do livre mercado seu fundamento de classificação social. 
Educação popular e sua renovação crítica: um diálogo com as Epistemologias do Sul

Não é por acaso que o "pensamento único" assume função, além de ideológica, normativa e racional para construir um consenso na sociedade e nas instituições (Estado) em torno desse programa neoliberal para legitimá-lo, o que implica deslegitimar outros, isto é, (re)produzir formas de não existências sociais, exclusão, sob o discurso da inclusão

\section{Educação Popular: um olhar sob o enfoque das Epistemologias do Sul}

Num contramovimento a esse movimento epistemológico e político-cultural hegemônico, Santos (2004) defende um paradigma emergente: Conhecimento Prudente para uma Vida Descente, que está a se engendrar a partir do Sul. Na sua proposta de outro paradigma de conhecimento, ele propõe superar a fragmentação natureza/sociedade; (re) colocar a relevância complexa da relação sujeito/objeto; aproximar as ciências naturais das ciências sociais e destas aos estudos das humanidades, fundando-se numa nova relação entre ciência e ética, substituindo a aplicação puramente técnica ou tecnicista da ciência pela sua aplicação edificante; e estabelecer uma nova relação entre conhecimento científico e as demais formas de saber, visando 206 transformar a ciência num novo senso comum; assenta-se numa acepção construtivista da verdade.

Para tanto, uma das teses defendida por Santos, Meneses e Nunes (2005, p. 97) é a de que: "A diversidade epistemológica do mundo é potencialmente infinita; todos os conhecimentos são contextuais e tanto mais o são quanto se arrogam não sê-lo". Essa tese se associa à outra, conforme a qual: "Todo conhecimento é parcelar e as práticas sociais só raramente assentam apenas numa forma de conhecimento". Esse paradigma emergente, portanto, implica, de um lado, uma contestação e desestabilização do paradigma dominante racionalista que se arroga o poder universalista de representar 0 mundo e determinar o caminho a ser seguido por todos os povos, impondo um padrão monocultural de pensar, agir, sentir e de ser; de outro lado, ajuda a pensar e criar o caminho à diversidade epistemológica no mundo, a partir da emergência e reconhecimento dos demais saberes e culturas, residindo a imperatividade do reconhecimento de seus lugares, territórios ou territorialidades do campo e cidade.

Isso se constitui em um pressuposto relevante para emergir com os saberes e culturas, modos de representar o existir dos povos excluídos do 
campo e da cidade, historicamente colocados na condição periférica e na ausência pela colonialidade do poder e do saber racionalista e pelo capitalismo. É nesse sentido que Santos (2006), num diálogo e polêmica com outras posições teóricas e epistemológicas contemporâneas, chama atenção para necessidade de se colocar a vista esses conhecimentos ausentes, emergi-los, realizando, assim, as "sociologias da ausência e da emergência", a fim de se desdobrar para uma "sociologia da tradução", produzindo a representação e o reconhecimento desses diversos saberes e sujeitos, através da "Ecologia de Saberes" em busca de um "pensamento pós-abissal" e da reinvenção da emancipação social (SANTOS, 2007).

A Ecologia de Saberes se constituí como "posição epistemológica" e meio para se pensar e materializar a "descolonização de saberes" e, por conseguinte, a marcha para "diversidade epistemológica" e "justiça cognitiva global". Santos, Meneses e Nunes (2005, p. 100) assinalam que ela é: "[...] a posição epistemológica a partir da qual é possível começar a pensar a descolonização da ciência e, portanto, a criação de um novo tipo de relacionamento entre o saber científico e outros saberes". Os referidos autores asseveram e advertem, ainda, que a "ecologia de saberes" é:

princípio de consistência que subjaz às constelações de conhecimentos que orientam as práticas sociais minimamente complexas. A transição da monocultura do saber científico para a ecologia de saberes será difícil porque, tal como aconteceu no processo de consolidação do paradigma da ciência moderna, envolve não só questões epistemológicas, como também questões econômicas, sociais e políticas (SANTOS, MENESES, NUNES, 2005, p. 101).

Um dos grandes desafios para ciência contemporânea é reconhecer os demais conhecimentos, produzindo a "justiça cognitiva", que está relacionada indissociavelmente à luta pela justiça social, cultural, política, econômica e ambiental. Isso implica imprimir e escrever a ciência no terreno, fundamentalmente ético-político e social do humano, da radicalização da democracia, da justiça, da liberdade, da igualdade na diversidade e da responsabilidade e conservação da natureza, basilar para toda forma de vida do planeta. Esse é um terreno de redefinição que desafia os movimentos sociais e a educação popular a se reencontrarem como protagonistas de novos caminhos na sistematização e produção do conhecimento e interconhecimento e na práxis 
Educação popular e sua renovação crítica: um diálogo com as Epistemologias do Sul

ético-política, social e pedagógica no mundo atual, forjando uma relação intermovimento entre os movimentos sociais emancipatórios e uma autoeducação, para construção de novos horizontes de sociabilidades em nível local e global de forma multidimensional (SANTOS, 2006a).

Com a crise do socialismo real e as demais mudanças em curso na sociedade capitalista, conforme Mejía (1996), os referenciais teórico-metodológicos críticos que davam sustentação e parâmetros para as ações e reflexões da educação popular e dos movimentos, como sujeitos da história, mostram-se fragilizados para fazer a contestação em face das novas problemáticas e demandas conjunturais. Isso impõe rever suas formulações e análises no cenário das últimas décadas entre os séculos XX e XXI, fato que, para o referido autor, se reacomodou o velho no novo, continuando a centrar as suas ações-reflexões com base na relação de poder unilateralmente macroestrutural: capital x trabalho, fazendo da educação popular uma educação doutrinária e dos novos movimentos nascentes velhos movimentos.

No tocante à forma de condução das ações e da dinâmica da educação popular e dos movimentos, segundo Mejía (1996), os vícios de organizações corporativistas foram introduzidos, o que implicou uma redistri208 buição de poder internamente nos movimentos e a definição da sua agenda de acordo com as diretrizes das organizações partidárias, isto é, por fora dos movimentos, desconsiderando os interesses maiores dos coletivos sociais e a autonomia deles, que foram usados como correntes de transmissão para projetar políticos e partidos e de assalto ao poder, fazendo da educação popular, em muitos casos, instrumento de formação de lideranças/quadros, concepção, que em quase nada se diferenciou da política tradicional, os lideres, figuras bem formadas em sua maioria falando pelos movimentos e povo, em repetidos cargos e mandatos. A luta pelos interesses coletivos, no entanto, passou a ganhar um enfoque gradualista, ao passo que a ascensão de partidos e políticos ao poder e socialmente sobrepujou as motivações e as necessidades dos coletivos, da sociedade. Esses foram transformados em autênticos trampolins e a educação popular uma mera transferidora da ideologia partidária para tal feito.

Desta forma, conduzindo de maneira expressiva a educação popular ao abismo da doutrinação, desvanecendo, assim, suas reais finalidades ético-políticas formativas e ampliando a descrença do conjunto da militância popular, dos trabalhadores/as e da sociedade nelas. Um dado significativo é 
a ausência de uma renovação dos representantes de organizações coletivas, quadros partidários e dos seus assessores, o que atropela o princípio da participação, organização e ação coletiva, princípios fundantes da educação popular.

Com o surgimento de muitas Organizações Não-Governamentais (ONGs), em direção contrária àquelas de final da década de 1970 e meados de 1980), elas passaram a elaborar, executar, assessorar e gerenciar uma grande quantidade de projetos, financiados com recursos públicos, privados nacionais e internacionais, ampliando, assim, seu campo de ação e de legitimidade junto às instituições oficiais, às agências financiadoras e à sociedade civil, colocando os movimentos numa condição secundária de atores sociais, visto que deslocava a direção do processo dos movimentos para as assessorias profissionais dessas organizações do Terceiro Setor. Mejía (1996). Ademais, impunha-se uma cultura política da luta e de educação para esses sujeitos coletivos, vinda de cima, de forma racionalista e hierárquica, arrefecendo e minando aquela que vinha de baixo, dos sujeitos coletivos e da sua educação popular orgânica a esses interesses concretos, sobretudo pelo fato de uma grande parte desses financiamentos estar atrelada a uma agenda oficial.

Com efeito, o quão, os múltiplos e emergentes temas sociais de outrora trazidos e colocados pelos movimentos sociais e pela educação popular no terreno social e público foram restringidos ou desfigurados de seus reais significados pelos partidos, pelas cúpulas sindicais, pelos intelectuais e pelas ONGs que passaram a atribuir mais importância, na prática, ao seu status de projeção pessoal, partidária e financeira, ainda que o discurso de esquerda da transformação social ainda seguisse e figurasse esvaziadamente sem sentido, nesses espaços. Como adverte Calado (2004), a esquizofrenia vem atravessando fortemente setores populares, esmaecendo a coerência entre teoria e prática, discurso e exercício ético-político.

De um lado, a pretensão de se ter, de antemão, um modelo acabado de sociabilidade, como se fora algo concebido e viabilizado fora do plano histórico. [...] Por outro lado, há que se atentar, não menos, ao risco muito presente em certa corrente "pós-moderna", de se presumir fadada ao fracasso toda tentativa de se desenhar, ainda que a largos traços, um horizonte alternativo de sociabilidade (CALADO, 2004, p. 5). 
Educação popular e sua renovação crítica: um diálogo com as Epistemologias do Sul

Paulo Freire (1987, 1992), em uma de suas assertivas acerca da construção da resistência e da superação de uma sociedade desumanizante pelas classes/grupos sociais excluídos, pelos movimentos e organizações populares e pela educação popular, defende que é imprescindível que se tenha consciência da sua presença histórica no mundo, a fim de se mover nele com criticidade e autonomia, para desvelar e revelar, denunciar a realidade opressora e excludente e anunciar outra realidade humanizante.

Calado (1998), influenciado por Freire, aponta que um, entre vários desafios e saberes postos pela atual conjuntura (e estrutura histórica) para a $E P$, envolve uma questão de natureza epistemológica, que está associada aos limites e possibilidades do que se vem denominando de realidade social. Ele defende que, para se apreender e continuar perseguindo a transformação da realidade humana, é necessário ir além da dimensão da realidade social, delimitada pelas esferas: econômica, política e cultural; é preciso associá-las a outras leituras científica e de mundo (multi/interdisciplinaridade) e dialogar com outras leituras, além das ciências, numa práxis multirreferencial. Isso exige uma nova postura epistemológica frente à realidade social com suas temporalidades, espacialidades, cotidianos e cotidianidades. Essa nova postura se

210 enraíza no diálogo entre múltiplos saberes e múltiplas dimensões e escalas, recolocando essa realidade diante da diversidade de novas leituras e da emergência de novos sujeitos capazes de exercer seu protagonismo.

Ao apontar para necessidade de uma dimensão lógico-epistemológica da EP intercultural que possibilite ampliar a lente crítica de compreensão da rede de complexidade que se formou na configuração e manutenção dessa sociedade capitalista globalizada, a fim de construir as balizas tanto para um enfrentamento e resistência ao projeto hegemônico, quanto vislumbrar novas lutas por emancipação, Fleuri assinala:

A lógica formal da não contradição e mesmo a lógica dialética da contradição não são mais suficientes para compreender os fenômenos complexos, como os da interdependência e da intercultura entre realidades muito diferentes, geradas no processo de globalização do mundo atual (FLEURI, 1998, p. 2).

Nesse sentido, a educação popular que se quer contemporânea de sua história e protagonista desse processo precisa apreender os fios que tecem e entrelaçam esse novo tecido social em suas várias dimensões e escalas, para 
recriar e reafirmar o seu território de saberes e contestação, de desestabilização do status quo vigente e de cultivação de novas sementes de possibilidades alternativas. Para isso, contudo, Freire adverte que uma consciência crítica, construída e elevada social, cultural, política e eticamente, não pode prescindir jamais do terreno das contradições e dos conflitos, onde ela se gera, entre classes/grupos sociais que fazem o movimento e engendram a sociedade, na qual se produzem e reproduzem os limites e possibilidades (FREIRE, 1987, 1992).

Nesse contexto, Freire (1992, 1996) coloca em questão a reinvenção crítica da pedagogia da esperança e do saber da problematização da história em contraposição ao discurso fatalista neoliberal que prega o "fim da história", sua inexorabilidade, para desvelá-lo e denunciá-lo, criando e apresentado novos caminhos possíveis. O saber ou os saberes, portanto, das contradições e dos conflitos - neles os limites e as possibilidades - que movem a história, que erguem, desmoronam e reerguem as sociedades são imprescindíveis, para a (re)construção desse protagonismo da educação popular e dos movimentos sociais populares nesse tempo-espaço, hoje, profundamente, esquizofrênicos e acinzentados. Nesse sentido, educação, política e poder são dimensões indissociáveis que se forjam em territórios histórico-sociais e político-culturais múltiplos por diversos sujeitos em disputa por seus interesses/projetos no tecido social. Nesse sentido, o reconhecimento da ampliação, do alargamento e da complexidade das formas de fazer e viver a política e dessas relações de poder nas esferas institucionais, grupais e interpessoais, constituem-se em um dos novos desafios teórico-metodológicos e epistemológicos da EP, a fim de:

a) Superar tanto uma interpretação unilateral e linear, da práxis macroestrutural da política e do poder, na qual residia a relação capital $x$ trabalho, sendo a classe operária sujeito único da história, quanto uma imposição da cultura política dominante conservadora liberal, que centra a política e poder nas instituições formais, ou seja, nos espaços públicos formais, como o executivo, legislativo e judiciário, sendo estes, no entanto, hegemonicamente, regulados e controlados pela racionalidade do livre mercado e de uma elite técnico-burocrática, que se apresentam como uno e onipotente.

b) Captar, desta feita, as lutas e práticas educacionais e socioculturais e sentidos da política que estão no terreno da periferia e dos (as) oprimidos (as), que simbolizam suas organizações e poderes, criados e recriados pelos diversos sujeitos coletivos e individuais em processos de exclusões, que inscrevem novas formas de resistência e caminhos alternativos, exigindo da educação popular 
Educação popular e sua renovação crítica: um diálogo com as Epistemologias do Sul

atinar, criticamente, para essa dimensão intercultural pedagógica que emerge desse território/lugar oprimido-invisível, que gesta uma cultura político-pedagógica da emergência, da assunção de sujeitos protagonistas contestadores e desestabilizadores do establishment e da ordem hegemônica neoliberal e construtores de novas utopias.

Com base nessas premissas, considera-se relevante penetrar nesse terreno oprimido-invisível do campo e da cidade-periferia, a fim de, parafraseando Freire (1987), mirar, admirar, re-admirar e evidenciar as experiências sociais, saberes, resistências e alternativas territoriais de sociabilidade que estão sendo gestadas por esses diversos sujeitos coletivos: os movimentos feminista, ambientalista, étnico-racial, de gênero, dos direitos humanos, da juventude etc., e dos movimentos sociais populares do campo e da cidade e da classe trabalhadora. Nos termos de Boaventura, trazer à baila, por meio da sociologia das ausências e da sociologia das emergências, uma ecologia de saberes e experiências sociais que alarguem, complexifiquem e diversifiquem o presente com novos sujeitos e alternativas plurais de sociabilidade (SANTOS, 2006b).

Aqui, ressaltam-se as lutas e experiências socioterritoriais, culturais, 212 ético-políticas, econômicas, ambientais e educativas dos movimentos sociais populares do campo, que vêm protagonizando e colocando essa territorialidade do campo em movimento, erguendo, como uma de suas matrizes pedagógicas, a pedagogia do movimento (ARROYO, 1999, 2002; CALDART, 2004; CORRÊA, 2007). Em relação a esse aspecto do movimento social como movimento pedagógico, importa assinalar que:

Essa reeducação da cultura política que vai pondo a educação e a escola popular na fronteira do conjunto dos direitos humanos se contrapõe ao discurso oficial, e por vezes pedagógico, que reduz a escolarização à mercadoria, o investimento, o capital humano, à nova habilitação para concorrer em um mercado cada vez mais seletivo (ARROYO, 2002, p. 165).

c) Ademais, esse mergulho no território do subterrâneo oprimido vai possibilitar capturar, apreender, também, as novas e diversas formas de opressão e de exclusão materiais e simbólico-culturais, criadas e recriadas, ampliadas e intensificadas pelo capitalismo e colonialismo contemporâneos. Isso possibilita uma apreensão mais consistente, articulando, indissociável e dialeticamente, 
micro e macro contextos, objetividade e subjetividade. Daí a relevância do Cotidiano enquanto malha de relações humano-sociais, defendido por Calado (1998), para reafirmar o revigoramento e atualização critica da educação popular.

Esse horizonte de ampliação e (re)contextualização da EP está bem explícito na compreensão de educação de Calado, para quem, ela se manifesta num imenso leque de espaços e dimensões sociais, na relação-interação entre Oikía e Polis (CALADO, 1998). Isso implica entender o espaço e a dimensão do exercício da educação popular além do terreno não oficial, com a finalidade de transformá-la e democratizá-la. Nessa esteira, é que Calado referencia o conceito de EP como:

Um processo educativo protagonizado por diferentes sujeitos (individuais e coletivos), normalmente pertencentes ou aliados à base da sociedade, cuja experiência pode se dar em espaços educativos formais e não formais numa dinâmica de formação contínua e numa perspectiva emancipatória e transformadora da realidade vigente, a partir da transformação cotidiana dos próprios protagonistas, que, graças ao exercício de sua dimensão docente e discente, se empenham no desenvolvimento integral de suas potencialidades subjetivas, étnicas, de gênero, de idade/geração, de classe, na relação com a Natureza e com o Sagrado, aspirando a construir uma sociedade justa, politicamente solidária e culturalmente plural (CALADO, 2003, p. 102).

Cabe fazer aqui um diálogo com Arroyo, a fim de repor e resignificar o sentido de existir da escola pública.

A escola é um dos lugares onde nos educamos. Os processos educativos acontecem fundamentalmente no movimento social, nas lutas, no trabalho, na produção, na família, na vivência cotidiana. E a escola que tem a fazer? Interpretar esses processos educativos que acontecem fora, fazer uma síntese, organizar esses processos educativos em um projeto pedagógico, organizar o conhecimento, socializar o saber e a cultura historicamente produzidos, dar instrumentos científico-técnicos para interpretar e intervir na realidade, na produção e na sociedade (ARROYO apud CORRÊA, 2005, p. 73). 
Educação popular e sua renovação crítica: um diálogo com as Epistemologias do Sul

Isso implica dizer e compreender que a educação não se reduz ao espaço formal, mas se estende para múltiplos espaços, o que (re)significa e supera o conceito de escola como único oráculo do aprender e do saber, em cujo centro está o professor, e o desafio de se situar a práxis político-educativa da escola em novos patamares, concebendo-a como um dos lugares onde nos educamos, sendo necessário que ela interaja com os demais saberes, espaços e sujeitos sociais, entendidos como produtores de outros processos e experiências educativas e existenciais, vislumbrando descolonizar as ciências, instituições e relações sociais.

Freire, em sua trajetória como educador popular, defendeu, incondicionalmente, uma ética universal do ser humano como um dos pilares básicos de sustentação de uma educação libertadora e humanizante. Com base nesse princípio, sua concepção e práxis de educação reconhece e luta pela condição ontológica do ser humano. Para Freire (1996, p. 33), mulheres e homens, como sujeitos histórico-sociais, "nos tornamos capazes de comparar, de valorar, de intervir, de escolher, de decidir, de romper, por tudo isso nos fazemos seres éticos. Só somos porque estamos sendo".

Essa retomada ampliada do sentido da formação humana pela edu214 cação popular repõe o sentido do reconhecimento da integralidade do ser humano e de sua condição de um ser de múltiplas e complexas relações, que se contrapõe a lógica hegemônica fragmentária, hierárquica, seletiva e disciplinar do controle sociopolítico cultural. Essa formação repõe o sentido e valor da sensibilidade e da alteridade, para afirmação, reconhecimento e representação das diferenças como necessárias para construção de sociabilidades alternativas democráticas interculturais emancipatórias.

Na combinação e articulação inseparável com essa perspectiva ética, a EP precisa fincar as estacas da necessidade e urgência da construção de uma concepção e prática educativa popular ambiental, que reponha a relação ser humano-natureza para além de um puro antropocentrismo, que concebe os recursos naturais como objetos de dominação da razão instrumental, que funda o paradigma de desenvolvimento eurocêntrico, que confunde, reduz e finda o desenvolvimento ao crescimento econômico e ao progresso sem fim, de modo desigual, excludente e predador dos recursos naturais (GADOTI, 2000). Essa nova perspectiva, também, precisa se constituir para além de um ecocentrismo, que superpõe à natureza, em grande medida, à natureza humana, que está fundada numa perspectiva biologizante do Norte, defensora das chamadas 
áreas protegidas, que excluem as populações humanas de suas comunidades, sustentando um protecionismo conservador. Seu caráter se assenta numa lógica neoliberal que beneficia os grandes grupos econômicos (DIEGUES, 2000).

Na corrente desse diálogo, Gadotti (2000) recoloca o olhar sobre o ambiente e a educação ambiental num patamar mais amplo, crítico e complexo. Nesse horizonte, ao se referir ao termo Ecopedagogia, que denomina, também, de Pedagogia da Terra, Gadotti explica que:

Ela só tem sentido como projeto alternativo global, em que a preocupação não está apenas na preservação da natureza lecologia natural) ou no impacto das sociedades humanas sobre os ambientes naturais (ecologia social), mas num novo modelo de civilização sustentável do ponto de vista ecológico (ecologia integral) que implica uma mudança nas estruturas econômicas, sociais e culturais (GADOTTI, 2000, p. 94).

Numa tentativa, também, de colocar a Educação Popular para além de uma e de outra dessas perspectivas - antropocêntrica e ecocêntrica -, vale construir um caminho novo e possível no diálogo com a perspectiva da etnoconservação apresentada e defendida por Carlos Diegues (2000), que propõe conceber a relação ser humano-natureza sem dicotomia e sem sobreposição, mas numa relação de diálogo e responsabilidade, onde social, cultural, político, econômico e ambiental são inseparáveis e se fundem numa outra lógica de sociabilidade, comprometida com os excluídos.

Essa perspectiva reconhece os modos de existir e saberes dos povos e comunidades tradicionais, sua diversidade sociocultural, associada à biodiversidade, suas potencialidades e técnicas para produzir novos territórios alternativos, articulando e combinando, indissociavelmente, o social, o cultural, o político, o econômico e o ambiental, o sagrado, o imaginário mítico e poético, para produzir e reproduzir seu existir material e simbólico-cultural sob novos padrões de relação ser humano-e-natureza. Por isso, como adverte Diegues (2000), o diálogo entre os conhecimentos dessas populações e o das demais ciências é apresentado como necessário e fundamental. Vale aqui registrar a necessidade de pesquisas que evidenciem a importância desses povos e comunidades tradicionais para a reinvenção da teoria crítica, da educação popular e de novas alternativas de sociabilidade. Um desses debates 
Educação popular e sua renovação crítica: um diálogo com as Epistemologias do Sul

que vêm ganhando visibilidade é o tema do Buen Vivir (Bem Viver ou Viver Bem) na América Latina (ACOSTA, 2016).

No tocante a essa última questão, se é preciso e urgente, de um lado, romper e superar com um modelo cientificista monocultural eurocêntrico, de corte capitalista e colonialista, de outro, é preciso não confundir e incorrer a um extremo oposto: ao populismo acadêmico, que absolutiza os saberes dessas populações, dados como perfeitos em si e, por conseguinte, acabados, sem limitações. Essas populações são detentoras de múltiplos saberes de limites e possibilidades no trato com o uso e significado dos recursos naturais e de seus territórios, que estão, em muitas situações, invisíveis, sobretudo, em função da lógica eurocêntrica produtivista e mercantil urbano-industrial e do agronegócio. Para esse padrão hegemônico, essas populações são classificadas como "primitivas" e "indolentes", não aptas ao desenvolvimento e à modernidade, por isso, precisam civilizar-se segundo esse padrão (ACOSTA, 2016). Isso é a expressão do que Boaventura (2006a) denomina de lógicas ou modos dominantes de produção da não existência social.

Essa é uma representação social construída e imposta que cobre e encobre essas populações/grupos e os seus territórios do campo, impondo216 - thes um imaginário social preconceituoso e excludente, que se põe como desafio para educação popular. Daí as noções de etnoconservação (DIEGUES, 2000), de síntese cultural (FREIRE, 1987), de Cotidiano (CALADO, 1998); de Ecopedagogia (GADOTTI, 2000) e de ecologia de saberes (SANTOS, 2006a) contribuírem, decisivamente, para construção desse novo e alternativo caminho intercultural e sustentável da educação popular, visto que ajudam a emergir essas populações na condição de sujeitos e protagonistas da construção de novas formas de sociabilidade

\section{Conclusão}

Esses pressupostos discorridos acima pretendem contribuir para recolocar o debate e renovação da Educação Popular, que envolve o diálogo com outros referenciais teórico-metodológicos e epistemológicos críticos e sinalizadores da reinvenção do processo de emancipação social. Isso implica colocar e visibilizar em cena um conjunto diverso de sujeitos sociais do campo e da cidade, como protagonistas, a partir desse terreno oprimido-invisível do Sul, 
como contraponto ao estabelecido oficialmente pela racionalidade e modelo de desenvolvimento conservadores hegemônicos.

Isso, também, implica envolver, reunir e combinar um conjunto de temas e tramas, do micro ao macro contexto, que desafiam à inter/trans/ multidisciplinaridade na apropriação, elaboração e reelaboração do conhecimento, que não pode prescindir do diálogo com os demais saberes da sociedade, mas precisa se fundar nessa dialogicidade e na ecologia de saberes. Envolve, ainda, um conjunto tempo-espaço diversos, do não formal ao formal, imprimindo um novo sentido para a escola pública como território de interação com os demais territórios da sociedade, suas práticas socioculturais, políticas, econômicas e ambientais, assim como concebendo os movimentos sociais e populares progressistas como protagonistas de uma pedagogia de emancipação. É, portanto, na apreensão e desvelamento dos limites, que se gestam as possibilidades reais de novos projetos de vida democrática.

\section{Notas}

1 Este artigo é resultado da dissertação de mestrado de Sérgio Roberto Moraes Corrêa, intitulada: "Educação Popular do Campo e Desenvolvimento Territorial Rural na Amazônia: uma leitura a partir da Pedagogia do Movimento dos Atingidos por Barragem", defendida no PPGE-UFPB sob a orientação do Prof. Dr. Severino Bezerra da Silva.

2 Santos (2006) usa a expressão "Epistemologias do Sul" para designar a metáfora do "sofrimento humano" provocado pelos sistemas capitalista, colonialista e patriarcado. Ele adverte para existência dos "terceiro-mundos internos" dentro dos países ricos, adverte que o Sul do Norte imperial apresenta, dialeticamente, o Sul Imperial, que está subordinado a esse Norte Imperial e se impõe sobre as vítimas e oprimidos do Sul.

\section{Referências}

ACOSTA, Alberto. O bem viver: uma oportunidade para imaginar outros mundos. Tradução: Tadeu Breda. São Paulo: Autonomia Literária/Elefante, 2016.

ARROYO, Miguel Gonzalez; Pedagogia em movimento: o que temos a aprender dos movimentos sociais? In: LIMA, Antônio Americo Biandi (Org). Trabalho e desenvolvimento na Amazônia: as experiências formativas da CUT. Porto Velho: Editora Imediata, 2002.

A educação básica e o Movimento Social do Campo. In: ARROYO, Miguel Gonzalez; FERNANDES, Bernardo Mançano. A educação básica e o Movimento Social 
Educação popular e sua renovação crítica: um diálogo com as Epistemologias do Sul

do Campo. Brasília: Articulação Nacional por uma Educação do Campo, MEC, 1999. (Coleção Por uma Educação do Campo, n. 2).

CALADO, Alder Júlio Ferreira. (Re) problematizando as concepções de educação popular. In. COSTA, Marisa Vorraber (Org.). Educação popular hoje. São Paulo: Loyola, 1998.

A Educação das pessoas jovens e adultas na perspectiva da educação popular: (re) problematizando termos da relação, no atual contexto sócio histórico. In: Direitos humanos X capital: potencializando a intervenção dos movimentos e organizações sociais de Base. João Pessoa: Ideia, 2003.

Tecendo saberes em busca de uma sociabilidade alternativa. Desafios da produção de saberes político-educativos. João Pessoa: Editora Ideia/Edições FAFICA. 2004.

CALDART, Roseli Salete. Pedagogia do movimento sem-terra. 3. ed. São Paulo: Expressão Popular, 2004.

CORREAA, Sérgio Roberto Moraes; Educação popular do campo e desenvolvimento territorial na Amazônia: uma leitura a partir da pedagógica do Movimento dos Atingidos por Barragem (MAB). 2007. 353f. Dissertação (Mestrado em Educação) - Programa de PósGraduação em Educação. Universidade Federal da Paraíba, João Pessoa, 2007.

DIEGUES, Antônio Carlos (Org.). Etnoconservação da natureza: enfoques alternativos.

218 Etnoconservação: novos rumos para proteção da natureza nos trópicos. 2. ed. São Paulo: Editora Hucitec, 2000.

DUSSEL, Enrique. 1492: o encobrimento do outro: a origem do mito da modernidade. Petrópolis-RJ: Vozes, 1993.

FLEURI, Reinaldo Matias (Org.). Educação Intercultural: desafios emergentes na perspectiva dos movimentos sociais. (Org.). Intercultura e movimentos sociais. Florianópolis. EditoraMover /Nup, 1998.

FREIRE, Paulo Reglus Neves. Pedagogia do oprimido. 17. ed. Rio de Janeiro: Editora: Paz e Terra, 1987.

Pedagogia da esperança: um reencontro com a pedagogia do oprimido. 15. ed. Rio de Janeiro. Editora Paz e Terra, 1992.

Pedagogia da autonomia: saberes necessários à prática educativa. 25. ed. São Paulo. Editora: Paz e Terra, 1996.

Pedagogia da indignação: cartas pedagógicas e outros escritos. São Paulo: Editora UNESP, 2000.

GADOTTI, Moacir. Pedagogia da terra. 5. ed. São Paulo. Editora Petrópolis, 2000. 
LANDER, Edgardo. Ciências sociais: saberes coloniais e eurocêntricos. In: A colonialidade do saber: eurocentrismo e ciências sociais. Buenos Aires: Conselho Latino-Americano de Ciências Sociais (CLACSO), 2005. (Coleção: Biblioteca de Ciências Sociais).

MEJÍA, Marco Raúl. A transformação social: educação popular e movimentos sociais no fim do século. São Paulo: Cortez, 1996.

QUIJANO, Anibal. Colonialidade do poder, eurocentrismo e América Latina. In: LANDER, Edgardo (Org.). A colonialidade do saber: eurocentrismo e ciências sociais. Perspectivas latino-americanas. Buenos Aires: Conselho Latino-Americano de Ciências Sociais (CLACSO), 2005. (Coleção: Biblioteca de Ciências Sociais).

SANTOS, Boaventura de S; MENESES, Maria P. G de; NUNES, João A. Introdução. Para ampliar o cânone da ciência: a diversidade epistemológica do mundo. In: Semear outras soluções: os caminhos da biodiversidade e dos conhecimentos rivais. Rio de Janeiro: Civilização Brasileira, 2005.

SANTOS, Boaventura de Sousa. A crítica da razão indolente: contra o desperdício da experiência. São Paulo: Cortez, 2001.

. (Org.). Os processos de globalização. In: A globalização e as ciências sociais. 2. ed. São Paulo: Cortez. 2002.

. (Org.). Introdução. Conhecimento prudente para uma vida decente: um discurso sobre as ciências revisitado. São Paulo: Cortez. 2004.

Para uma sociologia das ausências e uma sociologia das emergências. In: SANTOS, Boaventura de Sousa (Org.). Conhecimento prudente para uma vida decente: um discurso sobre as ciências revisitado. São Paulo: Cortez, 2004a.

Um discurso sobre as ciências. 3. ed. São Paulo. Editora: Cortez, 2005.

Do pós-moderno ao pós-colonial. E para além de um e outro. In: A gramática do tempo: para uma nova cultura política. São Paulo: Cortez, 2006.

A Universidade popular dos movimentos sociais. In: A gramática do tempo: para uma nova cultura política. São Paulo: Cortez, 2006a.

Para além do pensamento abissal: das linhas globais a uma ecologia de saberes.

Caderno Novos Estudos, Coimbra, n. 78, p. 3-46, 2007.

SANTOS, Boaventura de Sousa; MENESES, Maria Paula (Org.). Epistemologias do Sul. São Paulo: Cortez, 2010. 
Prof. Dr. Sérgio Roberto Moraes Corrêa

Universidade do Estado do Pará | Belém

Centro de Ciências Sociais e Educação

Programa de Pós-Graduação em Educação Grupo de Estudo e Pesquisa em Ações Coletivas, Desenvolvimento e Educação na Amazônia

E-mail | sergiorcm2001@yahoo.com.br

Prof. Dr. Severino Bezerra da Silva Universidade Federal da Paraíba | João Pessoa

Centro de Educação

Programa de Pós-Graduação em Educação Grupo de Pesquisa e Extensão Observatório da Educação Popular E-mail | severinobsilva@uol.com.br

Recebido 13 set. 2017

Aceito 16 out. 2017 